\title{
The Power Application Vacuum Switch
}

\author{
R. W. SORENSEN \\ HONORARY MEMBER AIEE
}

\begin{abstract}
Vacuum switching, which has attracted considerable attention recently in the public utility field, is actually far from a new concept. Much of the work done over the past 35 years in the development of the vacuum switch is reviewed.
\end{abstract}

$\mathrm{T}$ HREE CONCURRENT 1923 influences-a circuit breaker manufacturer's request for aid in developing better circuit breakers, the installation at California Institute of Technology (CalTech) of means for providing vacuum ambients for research programs, and a doubt about the completeness of knowledge regarding electric arc phenomena-synthesized a strong conviction that vacuum ambient power application switches could be made. This article describes the researches that made possible the development of power application vacuum circuit breakers.

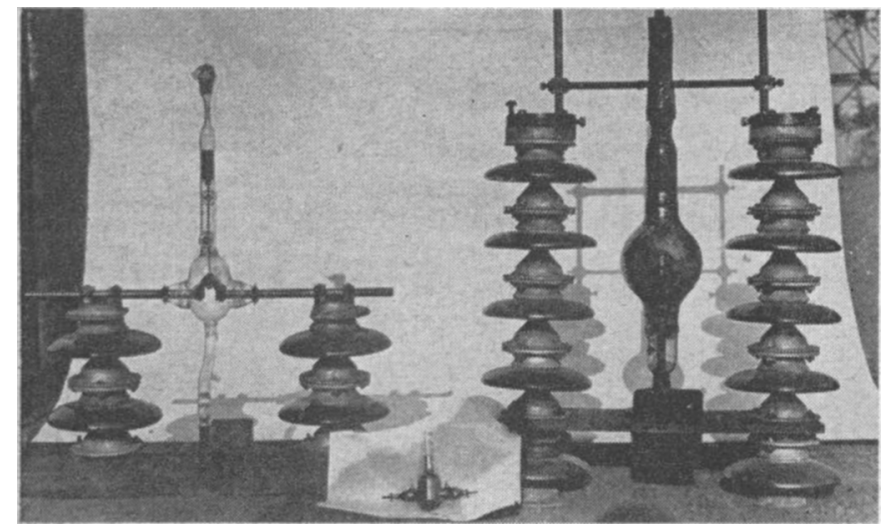

Fig. 1. First experimental power application vacuum switches. In the order of production: (Center) thousands of successful operations in free atmosphere at 2,300 volts, and with switch immersed in oil at 15 kv; (Left) opened generator short circuits at $13 \mathrm{kv}$ and 600 amperes; (Right) under like conditions, interrupted over 925 amperes, short circuits at about 42 kv.

In 1923, the need for a new approach to circuit breaker design was acute. Growing power demands and expanding interconnection programs had reached a magnitude that taxed to the limit the integrity of the best-made circuit breakers.

Two of the many circuit breaker stymies were the production of satisfactory bushings and the provision of maximum dielectric recovery. The spirit that solves such problems is well illustrated by remarks made 15 years before 1923 when one well-known electrical engi-

R. W. Sorensen, AIEE past president (1940-41), is professor emeritus of electrical engineering, California Institute of Technology, Pasadena, Calif. neer asked another, "How high will you go for transformer voltages?"; the reply was "We will build transformers for voltages as high as any for which you build circuit breakers." The stymie then, which happily no longer exists, was how to make satisfactory $110-\mathrm{kv}$ bushings.

A high-vacuum ambient, if such could be maintained in conjunction with switch-opening arcs, appeared to be the ideal way to provide quick dielectric recovery. Literature searches and discussions with engineers and physicists were quite discouraging, but when the late Dr. R. A. Millikan was asked for an opinion his reply was, "We will try it." A graduate student, H. E. Mendenhall, ran a series of tests and wrote a 1923 research progress report opening with "About October 1, 1923, under the direction of Dr. Millikan the design of a switch to operate in high vacuum, which had been suggested about August 15, 1923, by Professor Sorensen was begun." The report cites success for several hundred interruptions of a-c and d-c currents at 220 volts and for a-c circuits at 2,300 volts with the first successful vacuum switch, the small center item of Fig. 1. When tried at 15,000 volts. this switch arced over outside; but when immersed in oil, it made thousands of successful power circuit interruptions at this and higher voltages. His report also shows some success with fine outgassed copper wire fuses in highly evacuated sealed-off glass tubes. The progress report, a 1926 paper given at Salt Lake City, Utah, ${ }^{1}$ and a thesis by Mendenhall, ${ }^{2}$ together describe experiments with the three switches of Fig. 1. These experiments ${ }^{3}$ disclosed previously unknown arc phenomena and proved that vacuum switches are ideal for a-c circuits because they interrup: the current flow the first time the current value passes through zero. The arc energy is then very small, and the dielectric recovery against restrike is instantaneously very great. The switching arc explosive force which takes place in oiltype breakers and is transmitted to the switch container is absent when vacuum switches open circuits. The observed phenomena at switch openings are the arc, a small quantity of material discharged from the electrodes, and its deposit on the inside surface of the switch housing. This expelled material, it was discovered, occasionally would puncture the contact operating bellows and, even at times, the glass switch containers, unless shielding was provided or unless the glass was strong enough to prevent puncture by particle bombardment.

New arc characteristics which changed the then described arc theory were noted and found useful as guides to improvements in switches of other types dur- 


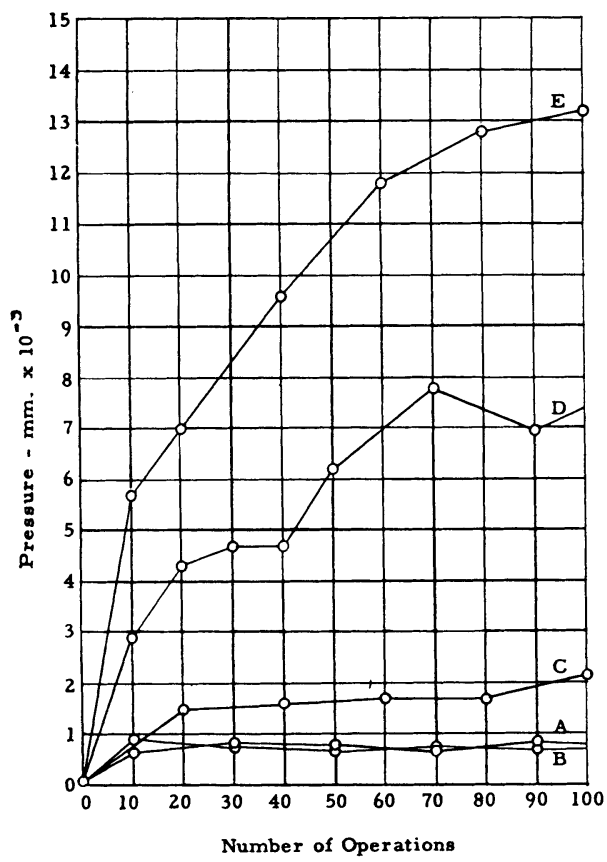

Fig. 2. Vacuum pressure curves, constant voltage 2,300 volts. Current densify, amperes per square inch: copper contacts, (A) 3,500, (B) 12,300, (C) 24,000; tungsten contacts, (D) 4,500 , (E) 11,250 .

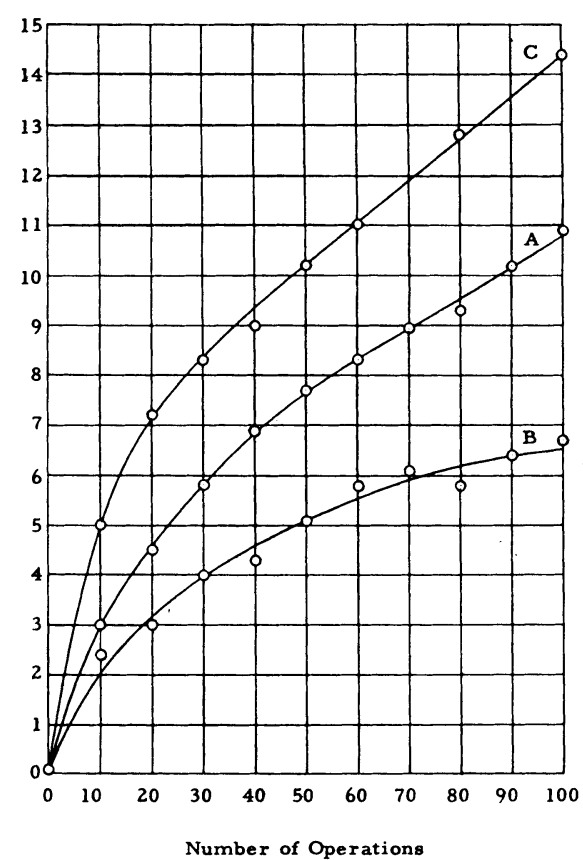

Fig. 3. Vacuum pressure curves, constant voltage $15 \mathrm{kv}$. Current density, amperes per square inch: copper contacts, (A) 370 , (B) 840; fungsien contacts, (C) 450.

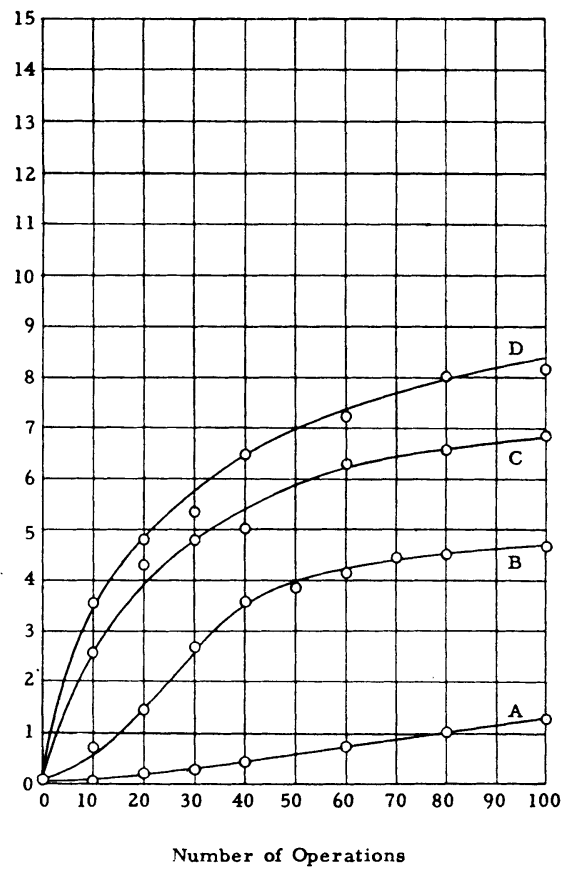

Fig. 4. Vacuum pressure curves, constant electrode current density 150 amperes per square inch. Interruption voltages, kv: (A) 15, (B) 25, (C) 30, (D) 35 . ing the 30-year hiatus between the breakthrough and the acceptance of power application vacuum switches. Computations showed that vaporizing the small amount of electrode material detached from the switch contacts when currents were interrupted could account for very little of the arc energy during interruption. Many interruptions deposited enough material driven from the electrodes on the inner surface of the glass switch containers to make much of them opaque. Thousands of operations, however, did not result in any flashover between switch terminals caused by the deposited material.

The vacuum switches of those researches were made successful by enclosing separable contacts of commercial copper or other metal in high-vacuum chambers and making enough current-interruption arcs while the vacuum was maintained to remove from the contacts the adsorbed gas. Sometimes very few arcs would suffice, and always enough arcs formed a successful vacuum switch.

Perhaps other experimenters who studied arcs in vacuo and concluded that vacuum switches could not be made reached that conclusion because of failure to arc the electrodes in vacuum the number of times required to remove from them the absorbed gas. ${ }^{4}$

Vacuum switches conditioned for a given voltage were always successful for voltages up to that value, but use at much higher voltages often required additional conditioning at the new voltage. Vacuum switch contacts once conditioned but by accident exposed to the air, at times as much as 24 hours, were restored to service with a very few switch opening arcs. On some occasions, after a shorter exposure, no new reconditioning was required. This indicated that perhaps absolutely gas-free electrodes could be operable as a vacuum switch without arcing, but the experiments of the breakthrough program did not decide that question.

The large right-hand switch of Fig. 1 in test runs at over 40,000 volts after being broken and open to the air for over 24 hours was again in good condition after one or two switch opening arcings. Apparently identical vacuum switches did not all function in the same way. To eliminate any uncertainty, a test parameter of 100 circuit interruptions was established, because switches operated that often with no failures continued for 1,000 or more operations without failure. This parameter should not be considered the minimum number of operations required to guarantee a stable condition, inasmuch as it was arbitrarily chosen without any effort to determine a true minimum number of required stabilizing operations.

Most of the loads used were low power factor (about $40 \%$ lagging). With few exceptions, the resultant switch opening overvoltage was smaller than for oil switches under the same conditions. It was realized, however, that vacuum switches with their quick breaks could result in high voltages when the load involved large energy stored in inductive circuits.

The difficulties encountered were obtaining good vacuum containers, good vacuum gauges, proper pumping equipment, and metal-to-glass seals that were vacuum tight, particularly large cylindrical ones-the only good cylindrical ones being supplied by Bell Telephone Laboratories, Inc. 


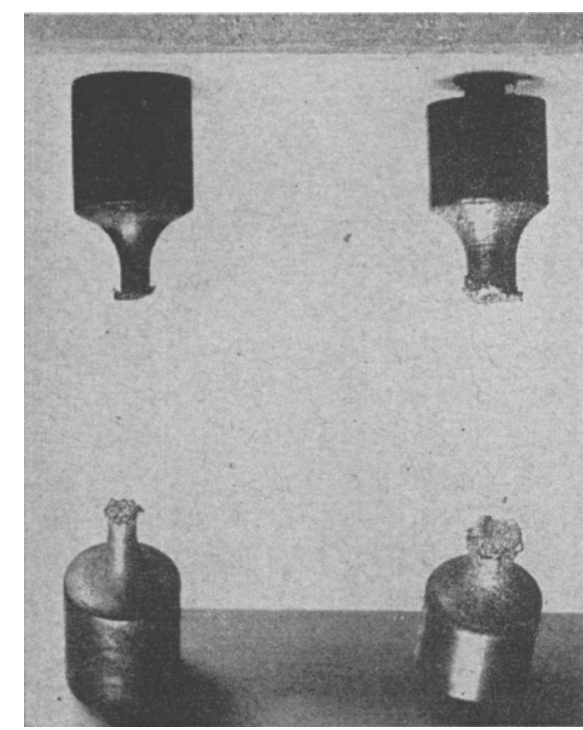

Vacuum-tight bellows were difficult to obtain but sylphon units selected from commercial lots provided the number required.

Mendenhall's successful experiments were supplemented by the researches of three other graduate students, J. H. Hamilton, C. D. Hayward, and F. C. Lindvall. These four and the author, aided by $\mathrm{R}$. A. Millikan's advice, devoted many hours to vacuum switch research until 1929, at which time the project was taken over by an industrial research laboratory.

Hamilton's thesis ${ }^{5}$ describes how, in one phase of his study, he used a magnetic oscillograph and a special circuit arrangement for measuring the low arc voltage, viz., 10 to 20 volts across vacuum switch opening contacts in circuits up to 15,000 volts. Tests on oil switches gave higher arc voltages and arc energies.

The results of two similar tests at low power factor inductive loads were as follows:

\begin{tabular}{lcc} 
& Vacuum Switch & Oil Switch \\
\cline { 2 - 2 }$I_{\text {rms }}$ & 58.1 amperes & 56 amperes \\
$E_{1 \text { ine }}$ & $16.2 \mathrm{kv}$ & $16.2 \mathrm{kv}$ \\
Time & 0.008 second & 0.05 second \\
Energy & 7.2 & 552 \\
& Ratio of energies $=\frac{552}{7.2}=77$ to 1
\end{tabular}

This thesis also discusses the then published arc theories as related to Hamilton's tests, and concludes that during arcing the current conduction apparently could not be solely by electrons but must require positive charges. Also, the evidence shows that the emission of electrons from an electrode produces a positive space charge just off the cathode, thus making feasible a large electron emission at low cathode drop. This analysis led to the conclusion that with no gas present in the electrodes, the arc extinction is at or near the time when the circuit current crosses zero value; the voltage reaching its normal value across the open switch with a time lag of about 0.0001 second.

A thesis by F. C. Lindvall ${ }^{6}$ contains numerous curves, some of which are reproduced as Figs. 2, 3, and 4. The ordinates of these curves are internal switch ambient pressure in thousandths of millimeters of mercury, the abscissas being number of switch operations. The curves show that the getter action of the detached electrode metal balances the tendency of that metal to soften the vacuum, the metal being deposited as a film on the inner surface of the switch housing. For this study, 100 operations per test were established after numerous tests on switches extended to 1,000 and more operations showed that the greater pressure changes occurred within the first 100 operations. Throughout the college researches, vacuum switching was successful for vacuums ranging from $10^{-2}$ to $10^{-5}$ millimeters of mercury. Figs. 2 and 3 show the effect of contact current density at two convenient laboratory circuit voltages. Fig. 4 shows the effects of voltage changes in a switch operating at constant contact current density. These curves show that both current and voltage influence the amount of gas desorption, but before 1931 it was known that single-break vacuum switches could handle voltages ranging up to over $80 \mathrm{kv}$, and at lower voltages could switch successively currents of over 3,000 amperes.

Fig. 5 shows two pair of switch copper contacts that continued to function successfully even when the current through them produced a softening temperature

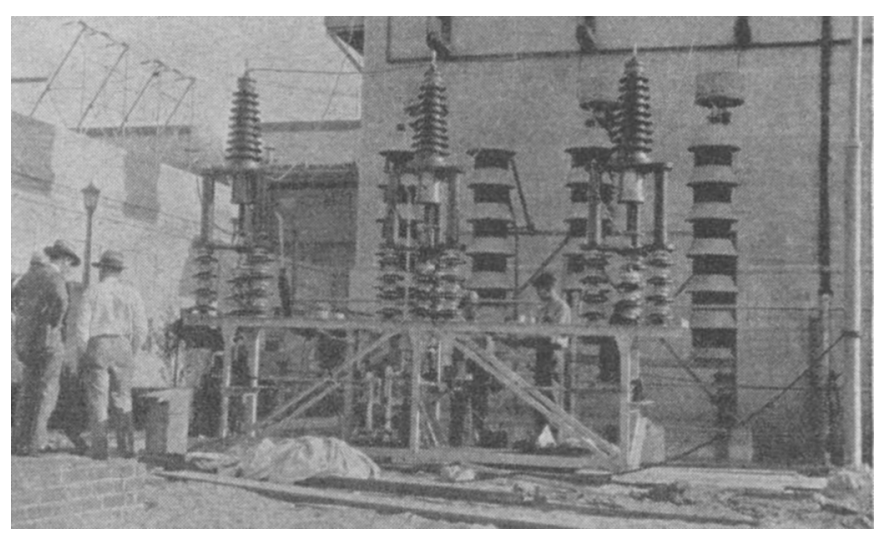

Fig. 6. No-glass 3-phase 60-kv vacuum switch.

that let the contact pressure cause the mushroom effect shown. These and other experiments produced temperature rise evidence that vacuum switches were best suited for interrupters rather than continuous current carriers.

A thesis by C. D. Hayward, ${ }^{7}$ the last report by the college vacuum switch research group, confirmed the findings made with the slower writing instruments. Three of the confirmed items were the apparent several time arc energy storage and releases during the brief arc durations, the getter action of expelled electrode particles during circuit openings, and evidence that often the very quick vacuum switch interruptions of inductive circuit currents resulted in lower surge-voltage drops across the opening switch contacts than were produced by oil switches used as alternates in the same 


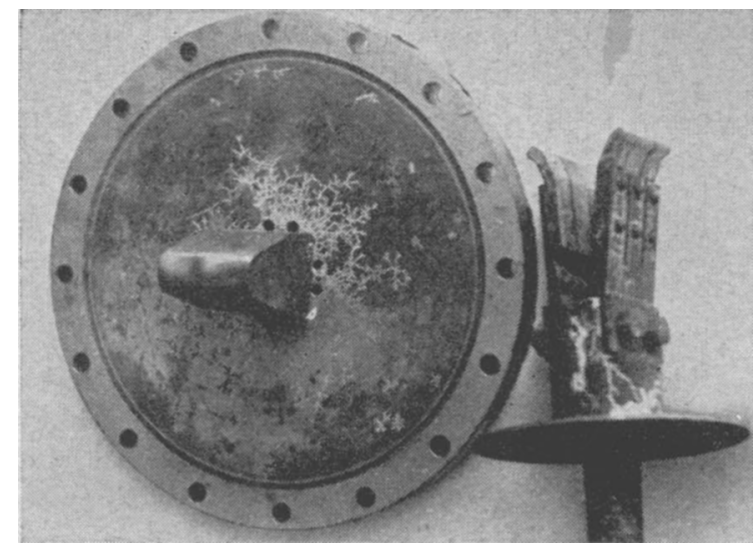

Fig. 7. Contacts used in vacuum switch shown in Fig. 6 .

test circuits. Also, this work checked Lindvall's determination that the softer the metal electrode, the more getter action and lower voltage surges at switch openings-aluminum in this respect being advantageous over copper, and copper advantageous as compared to tungsten.

The CalTech program included the production of some 3-phase switches for trial on power systems. Fig. 6 shows a design influenced by the success of large highvoltage X-ray tubes made of metal and porcelain. The joints were made vacuum tight by aluminum O-ring seals. The switch, as constructed, included a vacuum pump. The performance of this switch was erratic, with some successful switch openings interspersed with failures. Fig. 7 clearly shows the fault. The large amount of conditioned metal around the switch contacts made complete desorption of the gas impractical, so that when the arc of interruption reached a place not outgassed, the switch would not open the circuit. The collar on the movable electrode is a shield to prevent expelled particles from puncturing the copper bellows

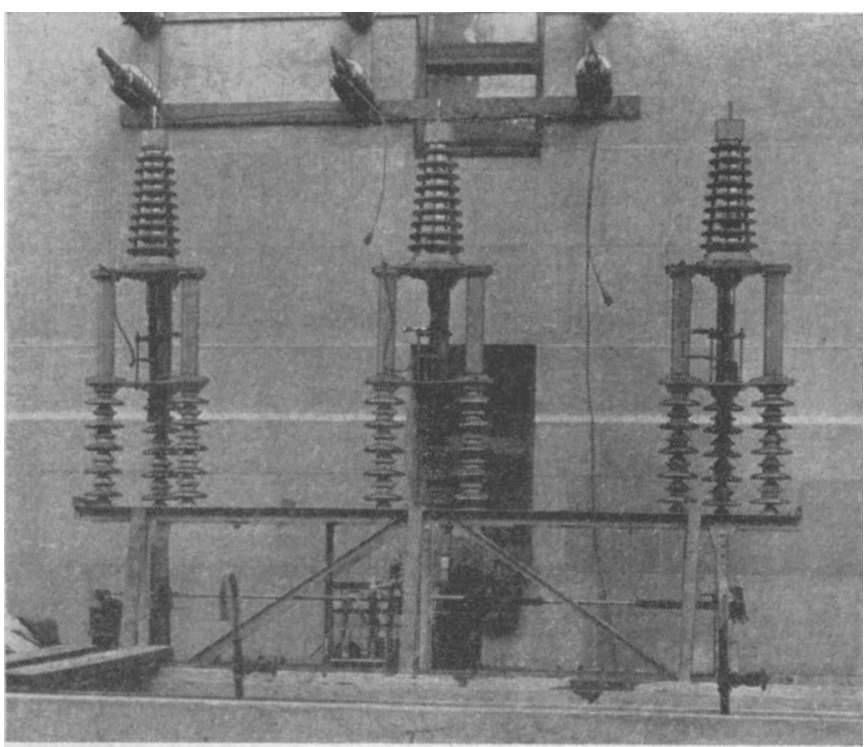

Fig. 8. Vacuum switch as shown in Fig. 6 rebuilt using glass confact enclosures. used to permit movement of the electrode. Experiments with high enough voltage and no current produced cold emission bombardment that punctured glass and bellows. Fig. 8 shows the Fig. 7 switch reconstructed with glass vacuum-tight housing protected by porcelain covers. Fig. 9 shows more clearly one pole of this arrangement. One criteria for this change was the determination by both Mendenhall and Lindvall that small interior volumes were preferable because the smaller volumes contain fewer particles, the agglomeration of which tends to produce conduction. The natural emigration from CalTech (via the $\mathrm{PhD}$ route) of Mendenhall (1927), Lindvall and Hamilton (1928), and

Fig. 9. Vacuum switch in glass housing and flexible bushing entrance detail.

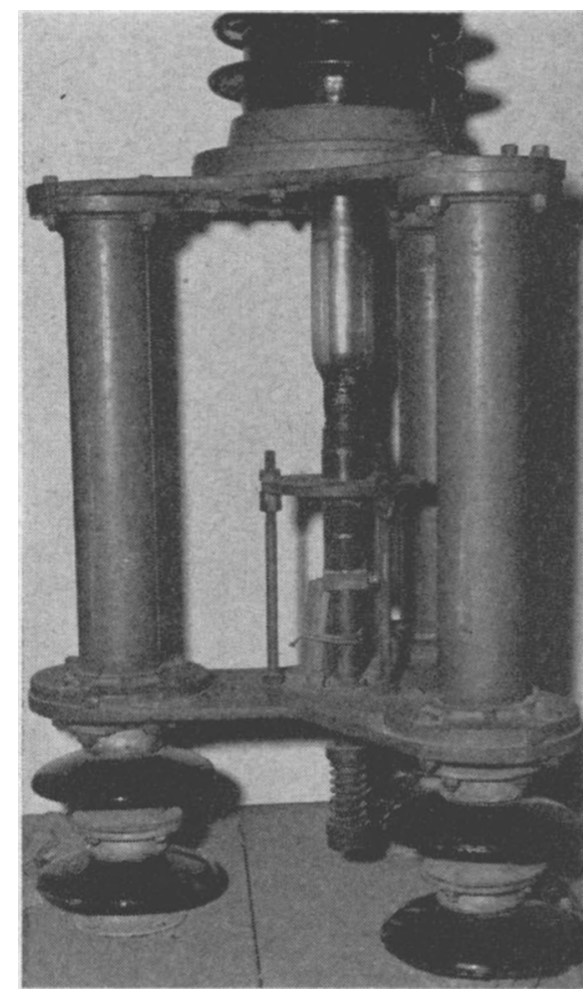

Hayward (1929), together with the transfer of the vacuum switch project to an industrial research laboratory, concluded the breakthrough.

The only American paper about power application vacuum switches between 1926 and 1955 was presented by R. Koller ${ }^{8}$ at the AIEE Summer Convention at Detroit, Mich., in 1946. That paper described experiments with a small vacuum switch in many ways similar to Lindvall's. The Koller experiments confirmed the earlier results and added new information. The two basic differences between the Koller experiments and those forming the basis of this paper are that Koller used d-c, whereas this paper is based on all a-c experiments with the exception of the first vacuum switch trials made by Mendenhall and Otis with d-c. Vacuum switch d-c and a-c performance differ because d-c has no current zerc time.

The hiatus period, made much longer than it otherwise might have been by the lean economic 1930-40 decade, was not devoid of vacuum switch interest. T. E. 
Browne, Jr., who discussed Koller's 1946 paper, ${ }^{8}$ compiled in that year a history of the vacuum switch for the Westinghouse Electric Corporation. ${ }^{9}$ This cites small current switch usage and a number of successful large current operations between 1923 and the 1955 breakthrough, but shows no power system usage.

In 1955 , tests on the $230-\mathrm{kv}$ lines of the Bonneville Power Administration system ${ }^{10,11}$ resulted in the return of the power application vacuum switch creation to the Pacific Coast. In 1955, a description of years of vacuum switch continuous service in the shops of the Jennings Company ${ }^{12}$ foretold an acceptance for power application switches, a prophecy which was forceably confirmed by three more recent AIEE papers. ${ }^{13-15}$

Fostered by the Jennings Radio Corporation and the Schwager Wood Corporation, the vacuum switch, by virtue of the vacuum technique knowledge gained during a 30-year time lag, has become the choice for hundreds of power system applications. Continued research and development will no doubt greatly increase the scope of their applications.

\section{REFERENCES}

1. Vacuum Switching Experiments at California Institute of Technology, R. W. Sorensen, H. E. Mendenhall. AIEE Transactions, vol. 45, 1926, pp. 1102-05. Discussions by J. Slepian, D. C. Prince, P. H. Thomas, and authors, pp. 1106-07.

2. The Interruption of Electrical Circuits in Vacuo, H. E. Mendenhall. $P h D$ Thesis, California Institute of Technology, Pasadena, Calif., 1927. 5. R. A. Millikan, R. W. Sorensen. U. S. Patent nos. 1784302, 1784303, issued Dec. 9, 1930 .

4. Temperature of a Contact and Related Current Interruption Problems, J. Slepian. Electrical Engineering, vol. 45, Oct. 1926, pp. 930-33. 5. Measurement of Arc Voltage Across Opening Switch Contacts, J. H. Hamilton. PhD Thesis, California Institute of Technology, 1928.

6. Contact Behavior and Gas Phenomena in a Vacuum Switch, F. C. Lindvall. $P h D$ Thesis, California Institute of Technology, 1928.

7. A Study of Vacuum Switch Arc Phenomena with the Cathode Ray Oscillograph, C. D. Hayward. PhD Thesis, California Institute of Technology, 1929 .

8. Fundamental Properties of the Vacuum Switch, R. Koller. AIEE Transactions, vol. 65, 1946, pp. 597-604. Discussion by T. E. Browne, Jr., p. 1141.

9. History and Special Status of the Vacuum Switch, T. E. Browne, Jr. Research Report R-94430-17-G, Westinghouse Electric Corporation, Pittsburgh, Pa., July 25, 1946.

10. Will Vacuum Switches Obsolete OCB's. Electrical West, San Francisco, Calif., vol. 115, July 1955, pp. 72-73.

11. Vacuum Switch is Revolutionary, Ibid., p. 84.

12. Vacuum Switch No Novelty. Ibid., Aug. 1955, pp. 78-79.

13. Vacuum Switches for Power Systems, J. E. Jennings, A. C. Schwager H. C. Ross. Electrical Engineering, vol. 75, no. 4, April 1956, pp. 350-54 AIEE Transactions, vol. 75, pt. III, June 1956, pp. 462-66.

14. The Role of the Vacuum Switch in Power Applications, T. W. Rit. tenhouse. Electrical Engineering, vol. 76, no. 3, March 1957, pp. 202-07.

15. Vacuum Switch Properties for Power Switching Applications, H. C. Ross. Paper 57-1100, scheduled for publication in AIEE Power Apparatus and Systems, 1958.

\title{
Fuse-Monitoring System for Multiple Fuse Circuits
}

\author{
G. R. LEZAN
}

\begin{abstract}
A circuit is described which will automatically provide an electric signal each time a power fuse blows, and also will provide a second distinct electric signal after a predetermined number of fuses have operated in a group of parallel cells.
\end{abstract}

$\mathbf{R}$ ECTIFIER CELLS in power semiconductor rectifier equipments are connected in parallel whenever it is desired to obtain output-current ratings exceeding the single-cell circuit rating. In practice, thus far, as many as 32 cells have been operated in parallel. In order to protect the rectifying equipment in the event of a rectifier cell failure,* power fuses are used

\footnotetext{
* The tcrm "failure" of a semiconductor rectifier cell as used in this article refers to a complete loss of the rectifying properties of the device. For all practical purposes, it is said then that the cell offers negligible opposition to electric current of either polarity.
}

in series with each cell or a pair of cells. When a cell failure occurs, the resulting short-circuit current interrupts the power fuse and, thus, the defective cell is disconnected from the circuit. The removal of a cell from the circuit represents the removal of a forwardconducting path from the group of parallel cells and results in an increase of current in the remaining cells of the group. The relative increase of current will depend upon the number of cells in parallel in the group. The greater this number, the smaller the relative current increase will be in each of the remaining parallel paths. When a cell failure occurs, depending upon the situation, it may or may not be necessary to remove power from the circuit and replace the defective cell in order to avoid current overload damage to the remaining cells.

G. R. Lezan is with the General Electric Company, Lynchburg, Va. 